This article was downloaded by: [University of Liege]

On: 9 February 2009

Access details: Access Details: [subscription number 787817762]

Publisher Informa Healthcare

Informa Ltd Registered in England and Wales Registered Number: 1072954 Registered office: Mortimer House, 37-41 Mortimer Street, London W1T 3JH, UK

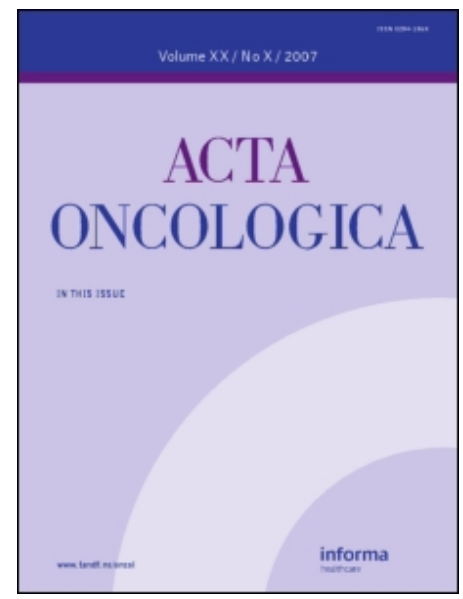

\title{
Acta Oncologica
}

Publication details, including instructions for authors and subscription information:

http://www.informaworld.com/smpp/title content=t713690780

\section{Effect of timing of surgery on survival after preoperative hyperfractionated} accelerated radiotherapy (HART) for locally advanced rectal cancer (LARC): Is

\section{it a matter of days?}

Philippe A. Coucke a; Markus Notter b; Maurice Matter c; Fabrizio Fasolini d; Jean-Marie Calmes c; Rolph Schlumpf ${ }^{\mathrm{d}}$; Norbert Schwegler b; Bernhard Stamm ${ }^{\mathrm{b}}$; Hu Phuoc Do e; Hanifa Bouzourene ${ }^{t}$

${ }^{a}$ Department of Radiation Oncology, Centre Hospitalier Universitaire Liège, ${ }^{b}$ Kantonspital Aarau, ${ }^{c}$

Department of Surgery, Centre Hospitalier Universitaire Vaudois, ${ }^{d}$ Kantonspital Aarau on behalf of all surgeons from public hospitals and private clinics, ${ }^{e}$ Department of Radiation Oncology, Centre Hospitalier Universitaire Vaudois, ${ }^{\dagger}$ Department of Human Pathology, Centre Hospitalier Universitaire Vaudois,

Online Publication Date: 01 December 2006

To cite this Article Coucke, Philippe A., Notter, Markus, Matter, Maurice, Fasolini, Fabrizio, Calmes, Jean-Marie, Schlumpf, Rolph, Schwegler, Norbert, Stamm, Bernhard, Do, Hu Phuoc and Bouzourene, Hanifa(2006)'Effect of timing of surgery on survival after preoperative hyperfractionated accelerated radiotherapy (HART) for locally advanced rectal cancer (LARC): Is it a matter of days?',Acta Oncologica, $45: 8,1086-1093$

To link to this Article: DOI: $10.1080 / 02841860600891317$

URL: http://dx.doi.org/10.1080/02841860600891317

\section{PLEASE SCROLL DOWN FOR ARTICLE}

Full terms and conditions of use: http://www.informaworld.com/terms-and-conditions-of-access.pdf

This article may be used for research, teaching and private study purposes. Any substantial or systematic reproduction, re-distribution, re-selling, loan or sub-licensing, systematic supply or distribution in any form to anyone is expressly forbidden.

The publisher does not give any warranty express or implied or make any representation that the contents will be complete or accurate or up to date. The accuracy of any instructions, formulae and drug doses should be independently verified with primary sources. The publisher shall not be liable for any loss, actions, claims, proceedings, demand or costs or damages whatsoever or howsoever caused arising directly or indirectly in connection with or arising out of the use of this material. 


\title{
Effect of timing of surgery on survival after preoperative hyperfractionated accelerated radiotherapy (HART) for locally advanced rectal cancer (LARC): Is it a matter of days?
}

\author{
PHILIPPE A. COUCKE ${ }^{1}$, MARKUS NOTTER ${ }^{2}$, MAURICE MATTER $^{5}$, FABRIZIO \\ FASOLINI $^{6}$, JEAN-MARIE CALMES ${ }^{5}$, ROLPH SCHLUMPF ${ }^{6}$, NORBERT SCHWEGLER ${ }^{2}$, \\ BERNHARD STAMM ${ }^{4}$, HU PHUOC DO ${ }^{7}$ \& HANIFA BOUZOURENE ${ }^{3}$
}

${ }^{1}$ Department of Radiation Oncology, Centre Hospitalier Universitaire Liège, ${ }^{2}$ Kantonspital Aarau, ${ }^{3}$ Department of Human Pathology Centre Hospitalier Universitaire Vaudois, ${ }^{4}$ Kantonspital Aarau, ${ }^{5}$ Department of Surgery Centre Hospitalier Universitaire Vaudois, ${ }^{6}$ Kantonspital Aarau on behalf of all surgeons from public hospitals and private clinics and ${ }^{7}$ Department of Radiation Oncology Centre Hospitalier Universitaire Vaudois

\begin{abstract}
We intend to analyse retrospectively whether the time interval ("gap duration" =GD) between preoperative radiotherapy and surgery in locally advanced rectal cancer (LARC) has an impact on overall survival (OS), cancer specific survival (CSS), disease free survival (DFS) and local control (LC). Two hundred seventy nine patients with LARC were entered in Trial 93-01 (hyperfractionated accelerated radiotherapy 41.6 Gy/26 Fx BID) shortly followed by surgery. From these 250 patients are fully assessable. The median GD of 5 days was used as a discriminator. The median follow-up for all patients was 39 months. GD > 5 days was a significant discriminator for actuarial 5 -years OS (69\% vs $47 \%$, p = 0.002$)$, CSS (82\% vs $57 \%, \mathrm{p}=0.0007$ ), DFS ( $62 \%$ vs $41 \%, \mathrm{p}=0.0003$ ) but not for LC (93\% vs $90 \%, \mathrm{p}=$ non-significant). In multivariate analysis, the following factors independently predict outcome; for OS: age, GD, circumferential margin (CM) and nodal stage (ypN); for CSS: GD, ypN and vascular invasion (VI); for DFS: CEA, distance to anal verge, GD, ypN and VI; for LC: CM only. Gap duration predicts survival outcome but not local control. The patients submitted to surgery after a median delay of more than 5 days had a significantly better outcome.
\end{abstract}

Surgery is the mainstay of treatment in rectal cancer [1-9]. The incidence of local recurrence should be well below $15 \%$ provided surgery is performed according to the now well accepted surgical standard, which is a total (TME) or a partial mesorectal excision with sharp dissection. Nevertheless, preoperative radiotherapy yields a significant better local control and in some trials a positive impact on survival [10-15]. In the randomized trials, in which a clear benefit in favour of 5 times 5 Gy has been reported, the interval between the end of radiotherapy and surgery is very short. In the Swedish rectal cancer trial (SRCT) the patients are submitted to surgery immediately after the weekend [15]. In the Dutch ColoRectal Cancer Group trial (DCRCG), the overall treatment time between the start of the radiotherapy and the surgery has to be within 10 days [13]. Therefore, in these trials the analysis of the impact of the timing of surgery after the end of radiotherapy is difficult to perform.

In Trial 93-01, a prospective non-randomized phase II trial on hyperfractionated accelerated radiotherapy (HART) in locally advanced resectable rectal cancer (LARC), there is a variation of the GD. Therefore, we are able to analyze the importance of the GD on patient's outcome.

\section{Patients and methods}

Trial 93-01 has been designed as a phase II trial to evaluate the efficacy of HART to increase the local control rate LARC. The feasibility of hyperfractionation and acceleration has been tested initially in a postoperative setting (Trial 89-01) [16]. In this time

Correspondence: Philippe A. Coucke, Department of Radiation Oncology, Centre Hospitalier Universitaire Liège, Belgique. Tel: +3243667949 . Fax: +32 436676 35. E-mail: pcoucke@chu.ulg.ac.be 
period, patients with non-readily resectable rectal cancer have been submitted to a preoperative hyperfractionated accelerated schedule of $32 \mathrm{~Gy}$. Eleven of 12 patients treated with this preoperative schedule underwent a curative resection (Trial 89-02; unpublished data). Subsequently, we started a new phase I study (Trial 92-01) increasing the preoperative total radiation dose to $41.6 \mathrm{~Gy}$ in LARC deemed to be resectable (preoperative HART followed by surgery after a short interval) [17].

Trial 93-01, conceived as a phase II trial, has been extended to a large prospective non-randomized study in order to have an accurate assessment of the impact of HART on the outcome of patients with LARC (i.e. survival and local control) [18]. This decision has been submitted and accepted by the Committee on Human Experimentation of the participating institutions. This is in agreement with the Helsinki declaration of 1975.

\section{Patient selection}

After oral informed consent, patients were submitted to a complete clinical examination and laboratory studies including blood count, biological assessment of renal and hepatic function and CEA-level. This was completed with chest X-ray, abdominal ultrasound, abdomino-pelvic computed tomography (CT) and a complete colonoscopy. The local extent of the tumor was assessed by digital rectal examination (DRE), transrectal ultrasound (TRUS) and pelvic CT-scan. The clinical T-stage (cT) was defined by TRUS and CT. All patients suffering from histologically confirmed rectal cancer staged cT3/T4 and any $\mathrm{N}$ stage or $\mathrm{cN}+$ and any cT-stage were eligible for Trial 93-01.

\section{Treatment characteristics}

All patients were treated with preoperative HART. Radiotherapy was performed with a linear accelerator with a minimal accelerating potential of $6 \mathrm{MV}$ with patients simulated and treated in prone position. A total dose of $41.6 \mathrm{~Gy}$ was applied in 26 fractions on 17 consecutive days (2 fractions a day with an interfraction interval of at least 6 hours). The dose per fraction was $1.6 \mathrm{~Gy}$. No irradiation was performed over the weekends. The dose prescription was done at the intersection of the four fields (boxtechnique). The requirement of dose homogeneity were a planning target volume (PTV) covered at least by the $95 \%$ isodose (lower limit) with an upper limit set at $110 \%$. The four fields were treated twice a day.

The rectal tumor and the mesorectal space were considered as part of the clinical target volume (CTV). The upper limit is set at the L5-S1 interspace in order to cover completely the anterior sacral surface [19-21]. The lower limit is defined as a function of the distance between the lower edge of the tumor and the anal verge. If the tumor is located at a distance of $\leq 5 \mathrm{~cm}$ from the anal verge, this latter is included in the treatment portal as part of the target volume. The lateral limits of the anteroposterior (AP) and postero-anterior (PA) fields are set at $1.5 \mathrm{~cm}$ from the internal pelvic bony rim. The AP-PA fields are completed with two lateral fields with the same upper and lower limits. The posterior limit of the lateral field are set behind the sacrum, whereas the anterior limit is located $3 \mathrm{~cm}$ anteriorly to the most anterior extension of the tumor as defined on CT. Individualized blocks are designed to exclude small bowel as much as possible from the radiation portals [22]. Inclusion of the external iliac nodes within the clinical target volume (CTV) - in contrast to internal iliac nodes - is not a protocol requirement.

The surgery is performed within one week after completion of the external irradiation. The surgical technique is decided by the individual surgeons. However, a TME with sharp dissection is strongly recommended for tumors in the lower half of the rectum. For tumors in the upper half a partial mesorectal excision is suggested $[1,2,5]$. When a sphincter sparing surgery is planned, we suggest the placement of a temporary diverting colostomy to protect the anastomosis. No radiation therapy is applied after surgery. No specific guidelines are defined in Trial 93-01 concerning adjuvant chemotherapy.

\section{Follow-up}

The follow-up of the patients in Trial 93-01 consists of patient history and physical examination. This is completed by CEA and TRUS after LAR. If patients are submitted to APR, TRUS is replaced by CT. This is performed every three months the first year and every six months thereafter. If the patients do not present at their bi-annual exam, the patients are contacted by phone or information is recovered through the general practitioner. Every single failure is recorded and verified by reviewing the multidisciplinary patient's record. Median follow-up is 39 months overall and for surviving patients 52 months. 


\section{Statistical methods}

Gap duration is used to discriminate between strata. The median value of 5 days is selected as the cut-off value ( $a$ priori hypothesis). Contingency analysis is performed for a series of tumor- and patient-related factors used as categorical data by GD (two-tailed Fisher's Exact test is used to test whether a significant difference can be observed $\mathrm{p} \leq 0.05$ ). Together with other patient- and tumor-related factors, we tested the predictive power of these variables using the product limit (Kaplan-Meier) method. Observed differences in survival curves between the predefined strata are tested with the log-rank test. A difference is considered significant provided a $\mathrm{p}$ value of $\leq 0.05$ is reached. Only factors reaching a significance level ( $p \leq 0.05$ log-rank) in the univariate analysis, are introduced in the Proportional Hazards model (Cox multivariate analysis), to assess whether they act as independent predictors of outcome.

Overall survival (OS) is calculated from initiation of HART until death, whatever the reason of death. Cancer specific survival (CSS) is calculated considering local recurrence, distant metastasis or death due to cancer as an event. Therefore, patients dying from unrelated causes are not added to the treatment failures. Events for disease free survival (DFS) are recurrent disease (local and/or distant), or death of any cause. Any clinically or radiologically detectable tumor, whether confirmed by biopsy or not, within the irradiated volume is labelled a local recurrence. We are aware that this definition does not allow the difference between an anostomotic failure, a nodal failure or a recurrence within the resection bed to be made. Every abdominal recurrence located outside of the irradiated pelvis or extra-abdominal failure, is labelled as a distant failure (metastastic disease).

All calculations are performed on a MacIntosh Powerbook G4 with JMP 5.0 software (SAS Institute Inc., Cary, NC, USA).

\section{Results}

Two hundred and seventy nine patients with LARC are enrolled in Trial 93-01 from 1993 to 2002. We report on 250 assessable patients. Twenty nine patients are excluded as these patients present with distant metastases at surgery $(n=24)$ or because of missing data $(n=5)$. For those patients with hepatic metastases at surgery, we consider that we could not label the treatment as curative and those patients are not considered eligible.

Age ranges from 26 to 85, with a median of 64 . There are 164 male and 86 female patients. The CEA level ranges fom 0.1 to $713 \mathrm{ng} / \mathrm{ml}$ (normal value $(<5 \mathrm{ng} / \mathrm{ml})$. The median distance to the anal verge is $5 \mathrm{~cm}$, measured by rigid rectosigmoidoscopy (mean $5.6 \mathrm{~cm}$, range: $0-15 \mathrm{~cm}$ ).

In this cohort of 250 patients, the clinical stage distribution is as follows: 4 cT2 (but with radiological suspicion of nodal involvement on CT), 201 cT3 and 45 cT4. At DRE the tumors are found clinically tethered or fixed in $78.4 \%$ of the cases. As neither TRUS nor CT could - at that time-provide sufficiently reliable information on clinical $\mathrm{N}$-stage $(\mathrm{cN})$, this variable is not analyzed [23,24].

All patients received HART according to the protocol. There are no reports of treatment interruption due to acute toxicity. The median gap duration is 5 days (range 1-120 days). The 75th percentile is 7 days and the 90th percentile is 12 days.

On the 250 patients included, a majority are submitted to a sphincter sparing procedure (SSP) (141 patients $=56.4 \%)$. The pathological stage distribution after radiotherapy (ypT) is as follows: 3 ypT0 (1.2\%), 8 ypT1 (3.2\%), 57 ypT2 (22.8\%), 161 ypT3 (64.4\%) and 21 ypT4 (8.4\%). Downstaging is observed in $38 \%$ of the cases. The median value for the clearance (defined as the distance between the radial resection margin and the deepest tumoral infiltration) is $3 \mathrm{~mm}$ (range $0-35 \mathrm{~mm}$ ). In 118 patients nodes are found positive (47.2\%), whereas in 57 patients $(22.8 \%)$ vascular invasion (VI) is reported by the pathologist. In 206 patients $(82.4 \%)$, the resection margins are considered microscopically negative. In the remaining 44 patients it is essentially the lateral resection margin which is involved (41/44).

The median follow-up duration is 39 months overall and 52 months for surviving patients. The actuarial 5 year results are as follows: for OS $59.6 \pm$ $3.7 \%$ (median not reached); for CSS $71.5 \pm 3.5 \%$ (median not reached); for DFS $53.3 \pm 3.6 \%$ (median: 79 months). Only 16 patients presented a local recurrence (crude incidence $6.4 \%$ ). The actuarial 5 -years local control rate is $91.7 \%$ (s.e. $\pm 2.2 \%$ ). See Figure 1.

The contingency analysis results are summarized in Table I. No significant association can be highlighted between any of the tested tumor- and patient-related factors and gap duration except for histopathological tumor differentiation. The tumor differentiation, however, used to define two strata, does not yield a significant difference in OS, CSS, DFS and LC.

The results of the univariate analysis are summarized in Table II. Only factors reaching a statistically significant $\mathrm{p}$-value of $\leq 0.05$ (log-rank) are listed. Patients with a longer GD ( $>5$ days) have a better OS, DFS and CSS (the quantitative data for each 

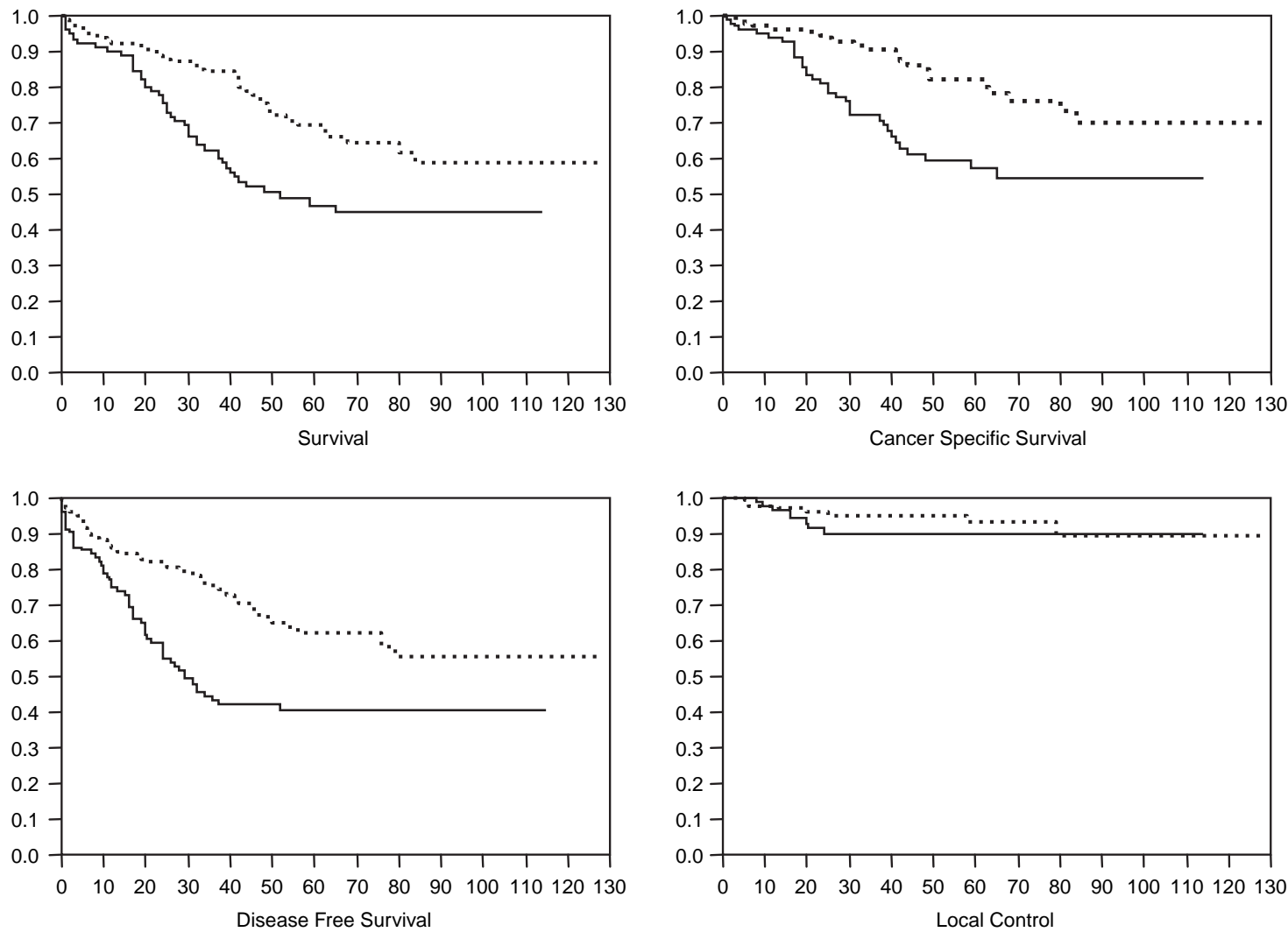

Figure 1. Overall survival, cancer specific survival, disease free survival and local control are plotted as a function of GD. If GD > 5 days see dotted line.

endpoint and for the two strata are reported in Table III). As there are no significant differences between the groups determined by GD in local recurrence rates at 5 years, the observed difference in DFS is mainly due to a difference in distant metastases.

For the multivariate analysis, factors reaching a p-value of $\leq 0.05$ (log-rank) in the univariate analysis are introduced in the proportional hazards model. The final model for OS, CSS, DFS and LC is tabulated with corresponding risk ratios and confidence limits (Table IV).

\section{Discussion and conclusion}

The actuarial local control rate in Trial 93-01 is $91.7 \%$ at 5 years. These results compare favourably well with the SRCT and DCRCG data $[13,15]$. If one compares directly the 93-01 results with SRCT and DCRCG, one should realize that in contrast to the two randomized trials (hypofractionation $=5 \times$ $5 \mathrm{~Gy}$ in one week followed by surgery after a short interval), there are no patients with clinical stage I disease in Trial 93-01.

The pattern of failure is dominated by the appearance of distant metastases. In the SRCT and the DCRCG the GD is rather homogeneous. In these trials one cannot assess whether GD has any influence on local control and distant metastases. In the SRCT, patients are operated immediately after the week-end break following the 5 times $5 \mathrm{~Gy}$ applied in one week [15]. In the DCRCG the overall treatment time (OTT), inclusive the gap, has to be contained within 10 days starting at day 1 of the radiotherapy although some variation in OTT has been reported [13].

In Trial 93-01, the variability in GD allows an evaluation of its potential impact on outcome. However, we should be extremely cautious as we cannot exclude that the present observation is just due to hazard. We cannot retrospectively assess the real reasons for this variability in GD. As a lot of surgical centers and surgeons are participating in Trial 93-01, we cannot eliminate selection biases and other confounding factors. Moreover, Trial 93-01 is a prospective non-randomized trial, not designed to answer the question of the importance of GD. The variability of the GD within Trial 93-01 is limited essentially within 10 days. Biases cannot be excluded.

This variability of GD is difficult to explain $a$ posteriori. It might in part be due to the important number of surgical centers involved in this trial (23) 
Table I. Contingency analysis for patient- and tumor related characteristics of potential prognostic importance (introduced as categorical data) by gap duration. A significant association between GD and any these characteristics a two-tailed Fisher's exact test yields a p-value $\leq 0.05$. D.a.m. - distance to anal margin. APR - abdominoperineal resection. T. volume - tumor volume (assessed on pathological specimens).

\begin{tabular}{|c|c|c|c|}
\hline & $\begin{array}{c}\mathrm{GD} \leq 5 \\
\text { days }\end{array}$ & $\begin{array}{c}\mathrm{GD}>5 \\
\text { days }\end{array}$ & $\begin{array}{c}\text { Fisher's test } \\
\text { p-value }\end{array}$ \\
\hline Female & 33 & 53 & \multirow{2}{*}{0.59} \\
\hline Male & 70 & 94 & \\
\hline Age $<64$ & 48 & 69 & \multirow{2}{*}{1.00} \\
\hline Age $\geq 64$ & 55 & 78 & \\
\hline $\mathrm{CEA} \leq 5 \mathrm{ng} / \mathrm{ml}$ & 63 & 101 & \multirow{2}{*}{0.22} \\
\hline $\mathrm{CEA}>5 \mathrm{ng} / \mathrm{ml}$ & 40 & 46 & \\
\hline D.a.m $\leq 5 \mathrm{~cm}$ & 50 & 81 & \multirow{2}{*}{0.37} \\
\hline D.a.m. $>5 \mathrm{~cm}$ & 53 & 66 & \\
\hline $\mathrm{cT}<4$ & 80 & 126 & \multirow{2}{*}{0.13} \\
\hline cT4 & 23 & 21 & \\
\hline APR & 45 & 63 & \multirow{2}{*}{0.90} \\
\hline Other than APR & 58 & 84 & \\
\hline Different. $<3$ & 79 & 91 & \multirow{2}{*}{0.02} \\
\hline Differentiation $\geq 3$ & 24 & 56 & \\
\hline Clearance $<3 \mathrm{~mm}$ & 25 & 38 & \multirow{2}{*}{0.88} \\
\hline Clearance $\geq 3 \mathrm{~mm}$ & 78 & 109 & \\
\hline $\mathrm{pT}>2$ & 75 & 106 & \multirow{2}{*}{1.00} \\
\hline $\mathrm{pT} \leq 2$ & 28 & 41 & \\
\hline Downstaging & 42 & 53 & \multirow{2}{*}{0.51} \\
\hline No downstaging & 61 & 94 & \\
\hline $\mathrm{pN}+$ & 47 & 71 & \multirow{2}{*}{0.70} \\
\hline pNO & 56 & 76 & \\
\hline No vascular invasion & 78 & 115 & \multirow{2}{*}{0.65} \\
\hline Vascular invasion + & 25 & 32 & \\
\hline Resection $\mathrm{R}_{0}$ & 88 & 118 & \multirow{2}{*}{0.32} \\
\hline Resection $\mathrm{R}_{+}$ & 15 & 29 & \\
\hline $\mathrm{T}$. volume $\leq 20 \mathrm{cc}$ * & 72 & 102 & \multirow{2}{*}{1.00} \\
\hline T. volume $>20 \mathrm{cc}$ & 31 & 45 & \\
\hline
\end{tabular}

Cut-off value for volume correponds to the $75^{\text {th }}$ percenrtile $\left(^{\star}\right)$.

and possibly to surgeon's misunderstanding of the protocol guidelines. We cannot exclude that tumors deemed to be marginally resectable, are submitted to a longer GD to improve resection rates after a potential downsizing. The published data on the impact of short gaps on tumor downsizing and downstaging are conflicting [25-28]. Whether a longer gap is important for increasing survival is still an open question [29]. What seems to be clear, however, is that one should try to obtain a clearance (=lateral resection margin) as large as possible [30-32].

Nevertheless, the GD remains in the present analysis a very powerful and independent prognostic factor for OS, DFS and CSS. The observed differences are highly statistically significant and of potential major clinical importance.

Local control rates are similar whether we are dealing with a short ( $\leq 5$ days) or a longer gap ( $>5$ days). However, one should remember that we are dealing with only 16 local events. Therefore, in
Table II. Univariate analysis of patient and treatment related characteristics. The cut-off values are tabulated for each of the parameters. If rated SS $\Delta$ there is a statistically significant difference between the strata with a p-value of $\leq 0.05$ log-rank test. $\mathrm{NS}^{\star}=$ difference not reaching a p-value $<0.05$ (log-rank) but reaching a $\mathrm{p}=0.03$ with the Wilcoxon test. APR abdominoperineal resection; LAR - low anterior resection; d.a.m. - distance to anal margin; clear - clearance i.e. lateral resection margin; VI - vascular invasion; GD - gap duration in days.

\begin{tabular}{llllll}
\hline & & OS & CSS & DFS & OS \\
\hline Age & $\leq 64$ & SS & & & \\
CEA & $\leq 5 \mathrm{ng} / \mathrm{ml}$ & SS & & SS & \\
d.a.m & $>5 \mathrm{~cm}$ & & & SS & \\
cT & & SS & SS & SS & SS \\
GD & $\leq 5$ days & SS & SS & SS & \\
Surg. & APR vs LAR & & & SS & \\
Clear & $<3$ mm & SS & SS & SS & SS \\
ypT & $\mathrm{T}_{1-2}$ vs $\mathrm{T}_{3-4}$ & SS & SS & SS & \\
ypN & + vs - & SS & SS & SS & \\
VI & + vs - & SS & SS & SS & \\
$\mathrm{R}_{0}$ & $\mathrm{R}_{0}$ vs $\mathrm{R}_{1-2}$ & SS & NS & SS & SS \\
\hline
\end{tabular}

the present analysis power is lacking to make any conclusion on the impact of GD on local control. GD seems primarily to influence the rate of distant metastatic disease. We searched the literature in order to find a possible explanation for the importance of GD on the appearance of distant metastases. There are apparently no data available neither clinical, nor experimental (in vivo animal models). In an attempt to explain this phenomenon, we intend to present four uncontrolled hypotheses which should obviously be viewed cautiously and submitted to experimental and clinical testing.

First of all, one can argue that quality of surgery may influence the occurrence of distant metastases. As shown by different groups, the quality of the surgery does indeed directly determine the local risk. However, better quality surgery has apparently no effect on the incidence of initial distant metastases [33].

Table III. Univariate analysis for the parameter GD. The cut-off value of $\leq 5$ days is used to define the two strata. For the 2- and 5years results, in the upper line are tabulated the values for the subgroup with a GD $\leq 5$ days, whereas the lower line represents the patients with a GD $>5$ days. If the median is not reached, this is labelled NR in the table. All survival figures are given in \% with the corresponding standard error.

\begin{tabular}{llrrl}
\hline & p-value & 2-years & 5-years & \multicolumn{1}{c}{ Median } \\
\hline OS & \multirow{2}{*}{0.002} & $75 \% \pm 0.05$ & $47 \% \pm 0.06$ & 51 months \\
& & $88 \% \pm 0.03$ & $69 \% \pm 0.05$ & NR \\
CSS & 0.0007 & $81 \% \pm 0.04$ & $57 \% \pm 0.06$ & NR \\
& & $94 \% \pm 0.02$ & $82 \% \pm 0.04$ & \\
DFS & 0.0003 & $55 \% \pm 0.05$ & $41 \% \pm 0.05$ & 28 months \\
& & $82 \% \pm 0.03$ & $62 \% \pm 0.05$ & NR \\
LC & NS & $90 \% \pm 0.03$ & $90 \% \pm 0.03$ & NR \\
& & $96 \% \pm 0.02$ & $93 \% \pm 0.03$ & \\
\hline
\end{tabular}


Table IV. Multivariate analysis of patient and tumor related factors. The second column corresponds to the cut-off value. For each of the parameters the p-value is listed (upper line) with the Risk Ratio (RR) and corresponding confidence limits (CL) (lower line). If the factor is not kept in the final model, this factor is mentioned in the table as not significant (NS). GD - gap duration; VI - vascular invasion; a.m. anal margin. Patients in the defined subgroup have a better prognosis if the $R R<1$.

\begin{tabular}{|c|c|c|c|c|}
\hline & Os & CSS & DFS & $\mathrm{LC}$ \\
\hline $\begin{array}{l}\text { Age } \\
\leq 64\end{array}$ & $\begin{array}{l}0.02 \\
0.77(0.61-0.96)\end{array}$ & NS & NS & NS \\
\hline $\begin{array}{l}\text { Distance to a.m. } \\
>5 \mathrm{~cm}\end{array}$ & NS & NS & $\begin{array}{l}0.002 \\
0.73(0.59-0.89)\end{array}$ & NS \\
\hline $\begin{array}{l}\text { CEA } \\
\leq 5 \mathrm{ng} / \mathrm{ml}\end{array}$ & NS & NS & $\begin{array}{l}0.04 \\
0.81 \\
(0.66-0.99)\end{array}$ & NS \\
\hline $\begin{array}{l}\text { GD } \\
\leq 5 \text { days }\end{array}$ & $\begin{array}{l}0.0002 \\
1.51(1.21-1.88)\end{array}$ & $\begin{array}{l}0.0009 \\
1.57(1.20-2.06)\end{array}$ & $\begin{array}{l}0.0002 \\
1.46(1.20-1.79)\end{array}$ & NS \\
\hline $\begin{array}{c}\text { Clearance } \\
>3 \mathrm{~mm}\end{array}$ & $\begin{array}{l}0.008 \\
0.74(0.59-0.92)\end{array}$ & NS & NS & $\begin{array}{l}0.002 \\
0.45(0.26-0.74)\end{array}$ \\
\hline $\begin{array}{l}\mathrm{pN} \\
-\mathrm{vs}+\end{array}$ & $\begin{array}{l}0.0000 \\
0.60(0.47-0.75)\end{array}$ & $\begin{array}{l}0.0002 \\
0.57(0.41-0.77)\end{array}$ & $\begin{array}{l}0.0000 \\
0.61(0.49-0.75)\end{array}$ & NS \\
\hline $\begin{array}{l}\mathrm{VI} \\
-\mathrm{vs}+\end{array}$ & NS & $\begin{array}{l}0.01 \\
0.69(0.52-0.91)\end{array}$ & $\begin{array}{l}0.04 \\
0.80(0.65-0.99)\end{array}$ & NS \\
\hline
\end{tabular}

It is tempting to attribute the observed difference in OS and DFS to a variation in the dynamics of growth of distant metastatic deposits and changes in angiogenesis and oxygen supply [34]. The question remains open why there should be such a large difference in outcome resulting from a rather small difference in GD. It is well known that irradiation does induce signalling cascades, and especially those cascades linked to angiogenesis. Over-expression of vascular endothelial growth factor (VEGF) has been described after preoperative radiotherapy in rectal cancer [35]. Overexpression of VEGF is also linked to hypoxia induced Hypoxia inducible factor HIF$1 \alpha$. HIF- $1 \alpha$ stimulates matrigel invasion by HCT116 human colon carcinoma cells in vitro [36]. Hypoxia in colorectal cancer promotes therefore an invasive phenotype. As metallothionein (MT) are considered by some authors as markers for residual hypoxia, we tested whether in a subgroup of patients issued from Trial 93-01 MT, predict outcome $[28,37]$. In our data set we were not able to confirm a relationship between the marker and patient outcome [28]. However, residual hypoxia at the end of HART as a stimulus for metastasis remains a plausible hypothesis provided there is a difference between strata in the level of hypoxia as a function of time after the completion of the irradiation. In order to highlight this difference, in vivo metabolic imaging with PET technology or dynamic contrast enhanced nuclear magnetic resonance technology could be an option to demonstrate this hypothesis.

In the context of angiogenesis induced by irradiation, it is interesting to note that a prolonged treatment with angiostatin is able to reduce the metastatic burden during radiation therapy [39]. The synergistic effect of a treatment with angiostatin and irradiation is already observed after a brief concomitant exposure in experimental conditions. This is particularly important as there is evidence that the treatment of the primary tumor by radiation or surgery results in an increased secretion of proangiogenic factors potentially stimulating the growth of micrometastases. In advanced colorectal tumors, the use of bevacizumab (Avastin ${ }^{\circledR}$ : Genentech, South San Francisco, Ca) as a monoclonal antibody directed against the vascular endothelial growth factor receptor, has been validated in phase III trials illustrating the importance of the pro-angiogenic factors in disease progression [40]. Combinations of bevacizumab and chemotherapy represent nowadays standard of care therapy for patients with metastatic disease in the United States although the mechanisms of its unique toxicity has not yet been fully characterized $[41,42]$. It is however unclear whether this approach is of any help in a neo-adjuvant setting combined to irradiation [43].

Another interesting observation is a three- to fourfold increase of active matrix metalloproteinases (MMP) after radiotherapy $[44,45]$. These zinccontaining enzymes are actively involved in the degradation of the extracellular matrix, and hence act as key-players in tumor invasion and spread. Moreover, there is evidence that these enzymes play a role in the angiogenesis process [46]. Kumar et al. advanced the hypothesis that radiotherapy leads to overexpression of type-IV collagenases in rectal cancer (especially MMP-2 and MMP-9) [44]. They postulate that this might be at the origin of the promotion of angiogenesis and in the re-establishment of invasion by remaining viable cancer cells in an attempt to resurrect the growth potential of the tumor $[44,45]$. A recent publication published by 
the same group shows that radiation results in increased MMP expression in vitro for a limited time period, resulting in an early increase in cell line invasion on Matrigel [47].

To explain our clinical observation, we should have a time dependency of the pro-angiogenic response and metastatic prone factors after radiotherapy. One might expect for example that the level of circulating VEGF, known to be induced by irradiation [48], encourages the growth of subclinical disease. This level might be different immediately after the end of the irradiation compared to the one observed after a long time interval. If cells are shed into circulation in optimal conditions, i.e. viable after irradiation, they might well end up in a general environment very suitable for metastasis. If the levels of pro-angiogenic factors and metastatic prone factors are falling as a function of time, surgery after a delay of a couple of days might reduce the metastatic potential of these tumor cells shed in the circulation at surgery.

We are currently investigating on surgical specimens whether there are significant differences in hypoxia levels (HIF-1a), apoptosis levels (surviving) [49], VEGF expression and type-IV collagenase levels between strata defined by GD. As we are analyzing the results on the surgical specimens only and not on biopsies, the surgery may confound the results as it can independently induce a number of stress factors. But this is potentially true for both groups whatever the GD. Another limitation of this approach is that we do not have the pretreatment values as we could not systematically recover the diagnostic biopsies. However, one can argue that a single biopsy is certainly not representative of the mean status of the tumor for a particular growth factor at the start of the treatment.

In conclusion, we did observe the impact of GD on OS, CSS and DFS but not on local control. Although we cannot exclude biases, we tentatively advance the hypothesis that changes in the microenvironment of the tumor induced by the irradiation might be time dependent and hence influence differentially the microscopic potential of surviving cells at surgery. This should be tested in animal models first before any extrapolation should be made to clinical practice.

\section{References}

[1] Heald RJ, Ryall RD. Recurrence and survival after total mesorectal excision for rectal cancer. Lancet 1986;1:147982.

[2] Heald RJ, Moran BJ, Ryall RDH, et al. The Basingstoke experience of total mesorectal excision, 1978-1997. Arch Surg 1998;133:894-9.
[3] Hermanek P, Hermanek PJ. Role of the surgeon as a variable in the treatment of rectal cancer. Sem Surg Oncol 2000;19: $329-35$.

[4] Kapiteijn E, Putter H, van de Velde CJH and cooperative investigators of the Dutch ColoRectal Cancer Group. Impact of the introduction and training of total mesorectal excision on recurrence and survival in rectal cancer in The Netherlands. Br J Surgery 2002;89:1142-9.

[5] MacFarlane JK, Ryall RD, Heald RJ. Mesorectal excision for rectal cancer. Lancet 1993;341:457-60.

[6] Martling AL, Holm T, Rutqvist L-E, et al. Effect of a surgical training programme on outcome of rectal cancer in the County of Stockholm. Lancet 2000;356:93-6.

[7] Quircke P, Durdey P, Dixon MF, et al. Local recurrence of rectal adenocarcinoma due to inadequate surgical resection: Histopathological study of lateral tumor spread and surgical excision. Lancet 1986;2:996-9.

[8] Quirke P. The pathologist, the surgeon and colorectal cancer-get it right because it matters. Prog Pathol 1998;4: $201-13$.

[9] Read TE, Myerson RJ, Fleshman JW, et al. Surgeon specialty is associated with outcome in rectal cancer treatment. Dis Colon Rectum 2002;45:904-14.

[10] Camma C, Giunta M, Fiorica F, et al. Preoperative radiotherapy for resectable rectal cancer. JAMA 2000;284:100815.

[11] Dahlberg M, Glimelius B, Pahlman L. Improved survival and reduction in local failure rates after preoperative radiotherapy: Evidence for the generalizability of the results of Swedish Rectal Cancer Trial. Ann Surg 1999;229:493-7.

[12] Glimelius B, Isacsson U, Jung B, et al. Radiotherapy in addition to radical surgery in rectal cancer: Evidence for a dose response effect favoring preoperative treatment. Int J Radiat Oncol Biol Phys 1997;37:281-7.

[13] Kapiteijn E, Marijnen CAM, Nagtegaal ID, et al. Preoperative radiotherapy combined with total mesorectal excision for resectable rectal cancer. N Engl J Med 2001;345:638-46.

[14] Pahlman L, Glimelius B. Pre- or postoperative radiotherapy in rectal and rectosigmoid carcinoma. Report from a randomized multicenter trial. Ann Surg 1990;211:187-95.

[15] Swedish Rectal Cancer Trial. Improved survival with preoperative radiotherapy in resectable rectal cancer. N Engl J Med 1997;336:980-7.

[16] Coucke PA, Cuttat J-F, Mirimanoff R-O. Adjuvant postoperative accelerated hyperfractionated radiotherapy in rectal cancer: A feasibility study. Int J Radiat Oncol Biol Phys 1993;27:885-9.

[17] Coucke PA, Sartorelli B, Cuttat J-F, et al. The rationale to switch from postoperative hyperfractionated accelerated radiotherapy to preoperative hyperfractionated accelerated radiotherapy in rectal cancer. Int J Radiat Oncol Biol Phys 1995;32:181-8.

[18] Coucke PA, Notter M, Stamm B, et al. Preoperative hyperfractionated accelerated radiotherapy (HART) in locally advanced rectal cancer (LARC) immediately followed by surgery. A prospective phase II trial. Radiother Oncol 2006; (in press).

[19] Hruby G, Barton M, Miles S, et al. Sites of local recurrence after surgery, with or without chemotherapy, for rectal cancer: Implications for radiotherapy design. Int J Radiat Oncol Biol Phys 2003;55:138-43.

[20] Steup WH, Moriya Y, van de Velde CJH. Patterns of lymphatic spread in rectal cancer. A topographical analysis on lymph node metastases. Eur J Canc 2002;38:911-8.

[21] Topor B, Ackland R, Kolodko V, et al. Mesorectal lymph nodes: Their location and distribution within the mesorectum. Dis Colo Rectum 2003;46:779-85. 
[22] Gunderson LL, Russell HA, Llewellynn HJ, et al. Treatment planning for colorectal cancer. Radiation and surgical techniques and value of small bowel films. Int J Radiat Oncol Biol Phys 1985;11:1379-93.

[23] Brown G, Radcliffe AG, Newcombe RG, et al. Preoperative assessment of prognostic factors in rectal cancer using highresolution magnetic resonance imaging. Br J Surgery 2003; 90:355-64.

[24] Brown G, Richards CJ, Bourne MW, et al. Morphologic predictors of lymph node status in rectal cancer with use of high-spatial-resolution MR imaging with histopathological comparison. Radiology 2003;227:371-7.

[25] François Y, Nemoz C, Baulieux J, et al. Influence of the interval between preoperative radiation therapy and surgery in downstaging and on the rate of sphincter-sparing surgery for rectal cancer: The Lyon R90-01 randomized trial. J Clin Oncol 1999;17:2396-402.

[26] Stein DE, Mahmoud NN, Rani Anné PR, et al. Longer time interval between completion of neoadjuvant chemoradiation and surgical resection does not improve downstaging of rectal carcinoma. Dis Colon Rectum 2003;46:448-53.

[27] Graf W, Dahlberg M, Osman MM, et al. Short-term preoperative radiotherapy results in down-staging of rectal cancer: A study of 1316 patients. Radiother Oncol 1997;43: $133-7$.

[28] Marijnen CAM, Nagtegaal ID, Klein Kranenbarg, et al. No downstaging after short term-preoperative radiotherapy in rectal cancer. J Clin Oncol 2001;19:1976-84.

[29] Onaitis MW, Noone RB, Fields R, et al. Complete response to neoadjuvant chemoradiation for rectal cancer does not influence survival. Ann Surg Oncol 2001;8:801-6.

[30] Marijnen CAM, Nagtegaal ID, Kapiteijn E, et al. Radiotherapy does not compensate for positive resection margins in rectal cancer patients: Report of a multicenter randomized trial. Int J Radiat Oncol Biol Phys 2003;55:1311-20.

[31] Nagtegaal ID, Marijnen CAM, Klein Kranenbarg E, et al. Circumferential margin involvement is still an important predictor of local recurrence in rectal carcinoma. Am J Surg Path 2002;26:350-7.

[32] Wiggers T, van de Velde CJH. The circumferential margin in rectal cancer: Recommendations based on the Dutch Total Mesorectal Excision Study. Eur J Cancer 2002;38:973-6.

[33] Köckerling F, Reymond MA, Altendorf-Hofmann A, et al. Influence of surgery on metachronous distant metastasis and survival in rectal cancer. J Clin Oncol 1998;16:324-9.

[34] Chmielarz A, Kryj M, Wloch J, et al. Prognostic factors for the time of occurrence and dynamics of distant metastases and local recurrences after radical treatment in patients with rectal cancer. Med Sci Monit 2001;7:1266-9.
[35] Nozue M, Isaka N, Fukao K. Over-expression of vascular endothelial growth after preoperative radiation therapy for rectal cancer. Oncol Rep 2001;8:1247-9.

[36] Krishnamachary B, Berg-Dixon S, Kelly B, et al. Regulation of colon carcinoma cell invasion by Hypoxia-Inducible Factor I. Cancer Res 2003;63:1138-43.

[37] Bouzourene H, Chaubert P, Gebhard S, et al. Role of methallotionein in irradiated human rectal carcinoma. Cancer 2002;95:1003-8.

[38] Miranda A, Janssen L, van Duijn W, et al. Prognostic significance of methallothionein in human gastrointestinal cancer. Clin Can Res 2002;8:1889-96.

[39] Gorski DH, Mauceri HJ, Salloum RM, et al. Prolonged treatment with angiostatin reduces metastatic burden during radiation therapy. Cancer Res 2003;63:308-11.

[40] Collins TS, Hurwitz HI. Targeting vascular endothelial growth factor and angiogenesis for the treatment of colorectal cancer. Semin Oncol 2005;32:61-8.

[41] Sanborn RE, Sandler AB. The safety of bevacizumab. Expert Opin Drug Saf 2006;5:289-301.

[42] Nygren P, Sorbye H, Österlund P, et al. Targeted drugs in metastatic colorectal cancer with special emphasis on guidelines for the use of bevacizumab and cetuximab: An Acta Oncologica expert report. Acta Oncol 2005;44:203-17.

[43] Hoff PM. Future directions in the use of antiangiogenic agents in patients with colorectal cancer. Semin Oncol 2004; 31(Suppl 17):17-21.

[44] Kumar A, Collins HM, Scholefield JH, et al. Increased typeIV collagenase (MMP-2 and MMP-9) activity following preoperative radiotherapy in rectal cancer. Br J Cancer 2000; $82: 960-5$.

[45] Kumar A, Collins H, Van Tam J, et al. Effect of preoperative radiotherapy on matrisylin gene expression in rectal cancer. Eur J Cancer 2002;38:505-10.

[46] Johnson MD, Kim HR, Chesler L, et al. Inhibition of angiogenesis by tissue inhibitor of metalloproteinase. J Cell Physiol 1994;160:194-202.

[47] Speake WJ, Dean RA, Kumar A, et al. Radiation induced MMP expression from rectal cancer is short lived but contributes to in vitro invasion. Eur J Surg Oncol 2005;31: $869-74$.

[48] Maniwa $Y$, Okada $M$, Ishii N, et al. Vascular endothelial growth factor increased by pulmonary surgery accelerates the growth of micrometastases in metastatic lung cancer. Chest 1998;114:1668-75.

[49] Rödel C, Haas J, Groth A, et al. Spontaneous and radiationinduced apoptosis in colorectal carcinoma cells with different intrinsic radiosensitivities: Surviving as a radioresistance factor. Int J Radiat Oncol Biol Phys 2003;55:1341-7. 